\title{
Enlarged uterus through a natural orifice: worth an effort? A randomized controlled trial
}

\author{
Pratima Mittal, Amreesh Andiliya, Reeta Bansiwal*, Jyotsna Suri, Sunita Singal
}

Department of Obstetrics \& Gynaecology, VMMC \& Safdarjung Hospital, New Delhi-110029, India

Received: 27 October 2014

Accepted: 11 November 2014

\author{
*Correspondence: \\ Dr. Reeta Bansiwal, \\ E-mail: drreetabansiwal@gmail.com
}

Copyright: (c) the author(s), publisher and licensee Medip Academy. This is an open-access article distributed under the terms of the Creative Commons Attribution Non-Commercial License, which permits unrestricted non-commercial use, distribution, and reproduction in any medium, provided the original work is properly cited.

\begin{abstract}
Background: The objective was to compare the efficacy, safety and patient satisfaction of the Non-Descent Vaginal Hysterectomy (NDVH) with Total Abdominal Hysterectomy (TAH) in benign enlarged uterus.

Methods: This was a prospective Randomized comparative study. A total of 60 subjects were randomly divided into VH and TAH groups (Group A, group B), by sealed opaque envelope, each comprising 30 subjects. Subjects having uterus of more than 12 weeks size requiring hysterectomy for benign pathology and non-prolapsed uterus were included in the study. Corporal bisection, morcellation, myomectomy, coring and combination of these were used as debulking procedures.

Results: We could do all the VH successfully with no conversion to laparotomy and $100 \%$ success rate. The mean uterine size was $420.00 \mathrm{~g} \pm 117.24$ in group $\mathrm{A}$ and $454.33 \mathrm{~g} \pm 52.50$ in group $\mathrm{B}$, mean operative time taken was more in group $\mathrm{B}$ as compared to group $\mathrm{A}$, though not statistically significant $(97 \pm 4.46 \mathrm{~min}, 100 \pm 7.27 \mathrm{~min}$; $\mathrm{P}=$ 0.621). The mean blood loss, haemoglobin decrease and the Blood Transfusion was significantly lesser in VH group as compare to TAH group $(251.13 \pm 57.98 \mathrm{ml}, 327.33 \pm 58.54 \mathrm{ml} ; \mathrm{P}=0.000)$. There was no visceral injury in either group, though postoperative fever and wound infection were more in the TAH group than VH group.

Conclusions: VH is safe and should be offered as the first surgical choice in women with uterine enlargement due to benign reasons and non-prolapsed uterus where feasible, and should be included in training program for residents and postgraduates trainees. It is definitely a surgical challenge worth the effort.
\end{abstract}

Keywords: NDVH, TAH, Coring, Bisection, Morcellation

\section{INTRODUCTION}

Hysterectomy, the surgical removal of the uterus, is one of the most common gynaecological surgery performed worldwide. ${ }^{1}$ The majority of hysterectomies are performed for benign indications such as fibroid uterus. ${ }^{2}$ Hysterectomies are performed vaginally, abdominally, or with laparoscopic or robotic assistance.

When choosing the route and method of hysterectomy, the route of the surgery is decided according to the medical needs of patient, cost effectiveness and safety of the procedure. The two routes are not competitive procedures but each has its own place in the operative armamentarium of the gynecologist. Evidence demonstrates that, in general, vaginal hysterectomy is associated with better outcomes and fewer complications than laparoscopic or abdominal hysterectomy. A Cochrane review of 34 randomized trials of abdominal hysterectomy, laparoscopic hysterectomy, and vaginal hysterectomy, including 4,495 patients, concluded that vaginal hysterectomy has the best outcomes of these three routes. ${ }^{3}$ Moreover, $\mathrm{VH}$ has also been perceived as a scarless, minimal access surgery, with the added advantage of reduced cost. When it is not feasible to perform a vaginal hysterectomy, the choice is between abdominal hysterectomy, laparoscopic hysterectomy and robot-assisted hysterectomy. ${ }^{4}$ Conventionally in low resource setting TAH is the first choice for enlarged uterus. 
NDVH is routinely done for uterine size less than 12 weeks in our institution. Keeping in view that NDVH could substantially reduce the post-operative morbidity, decrease the cost and the duration of hospital stay, we planned to expand the horizon by studying the feasibly of NDVH in women having benign gynaecological disorders with enlarged uterus and also compare their outcome with the conventional approach of abdominal hysterectomy performed for similar indications.

\section{METHODS}

This was a prospective Randomized comparative study, conducted in the department of obstetrics and gynaecology of tertiary care hospital from May 2012 to March 2013 after taking approval from ethical committee of the hospital.

A total of 60 subjects were randomly divided into $\mathrm{VH}$ and TAH groups (Group A, group B), by sealed opaque envelope, each comprising 30 subjects. Subjects having uterus of more than 12 weeks size requiring hysterectomy for benign pathology and non-prolapsed uterus were included in the study, whereas subjects with uterus $<12$ weeks, nulliparity, previous pelvic surgery including cesarean section, PID and malignancy were excluded from the study. Detailed history and examination were followed by haematological, biochemical investigations, Pap's smear, endometrial aspiration, ultrasound pelvis to rule out any pelvic pathology and quality of life assessment scored with SF-36 performa. All women satisfying inclusion criteria were recruited, counselled and randomised to either $\mathrm{VH}$ or $\mathrm{TAH}$. Those who were willing to participate in the study were asked to sign an informed consent form.

The operations were performed by the same team of surgeons. All surgeries were performed under regional (spinal) anaesthesia. Preoperative prophylactic antibiotic consisting of $1.2 \mathrm{gm}$ of coamoxiclav was given intravenously at induction of anaesthesia. The same was repeated 12 hourly for next 24 hours as per hospital protocol.

\section{Surgical technique}

NDVH - The patients were placed in dorsal lithotomy with both hips and knees hyperflexed and a 15-30 degree head down tilt. After cleaning and draping the patient, the bladder was evacuated with a metal catheter and cervix was held with vulsellum. Circumferential incision was made around the cervix, pubo-vesico-cervical ligament was cut and bladder mobilized upwards. Both anterior and posterior pouches were opened one after another. Uterosacral and cardinal ligaments were clamped, cut and ligated. Clamping of uterine vessels was done bilaterally. For debulking the bigger sized uterus, morcellation techniques like uterine bisection, myomectomy, coring or combinations of these were performed as and when required. In case of fibroid with bigger sized uterus bisection was done after ligating the uterine arteries and myomectomy was done to ease limitation of space for further proceedings. In case of fundal fibroid only those myomas were removed which were interfering with delivery of the fundus.

In total hysterectomy, last clamp was on uterine cornua containing round ligament, ovarian ligament and medial part of fallopian tube. After delivery of the uterus hysterectomy was completed in a usual fashion. As we took only perimenopausal women and hysterectomy was done only for benign reasons, ovaries were not removed. The vaginal cuff was closed with no. 1-0 vicryl and vaginal pack was placed and indwelling Foleys catheterization done till next morning.

The patients who were randomized to undergo abdominal hysterectomy were also given regional anaesthesia. Prophylactic antibiotic was given to all the patients as in group A as per hospital protocol.

The abdominal hysterectomy was performed as per the standard technique.

The parameters that were evaluated were uterine weight, operative time, estimated blood loss during surgery, intraoperative complications, haemoglobin difference before and after operation, need for analgesia, postoperative course including post-operative complications, mobilization after surgery time of bowel movements, and oral intake and length of hospital stay.

The operative time was defined as the time from initial incision to the end of the surgery which was the point of vaginal/abdominal closure, excluding the anaesthesia period.

The blood loss during surgery was estimated by weighing the mops, every gram of weight gain was taken as equivalent $\mathrm{ml}$. of blood loss. The blood in the suction bottle was also added to this figure to calculate the total blood loss. 5

The need for analgesia in the form of diclofenac Sodium $200 \mathrm{mg}$ skin patches was recorded. In first 24 hours, Severity of pain was measured in both groups with Visual Analogue Scale (VAS).

The patients were followed at 6 weeks and 3 months and were asked about their clinical course and their quality of life with the help of SF36 performa.

Statistical analysis of the data was performed with SPSS, version 10.0 software (SPSS inc, Chicago III). Analysis of continuous data and discrete data was done with Mann-Whitney $\mathrm{V}$ test and $\mathrm{x}^{2}$ analysis respectively. A probability value of $<0.05$ was considered statistically significant. 


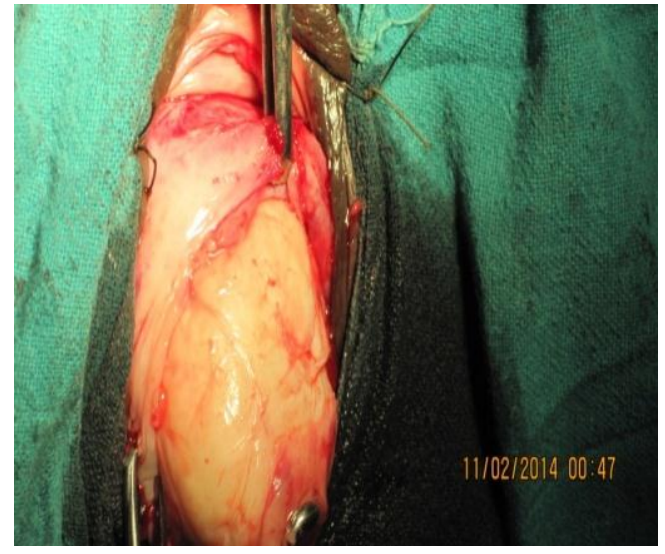

Figure 1: Debulking technique: myomectomy.

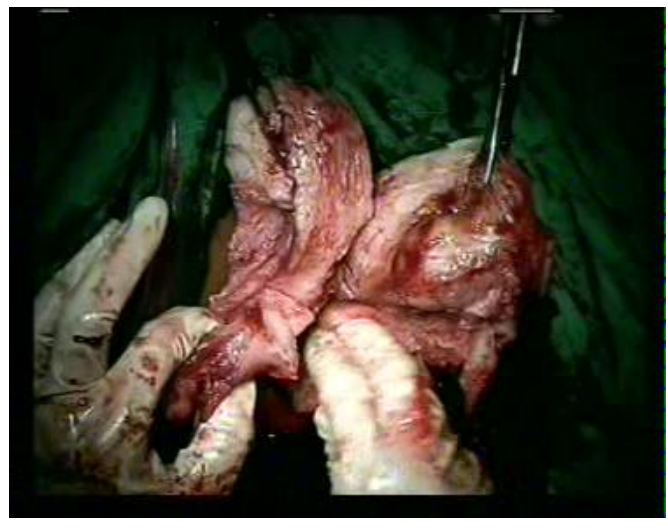

Figure 2: Debulking technique: bisection.

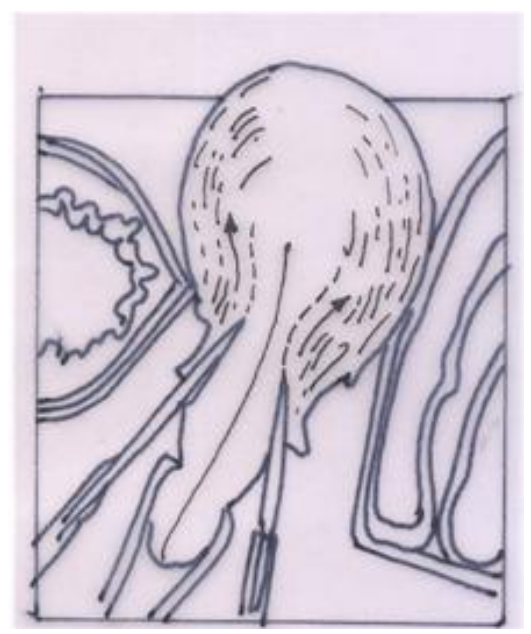

Figure 3: Debulking technique: coring.

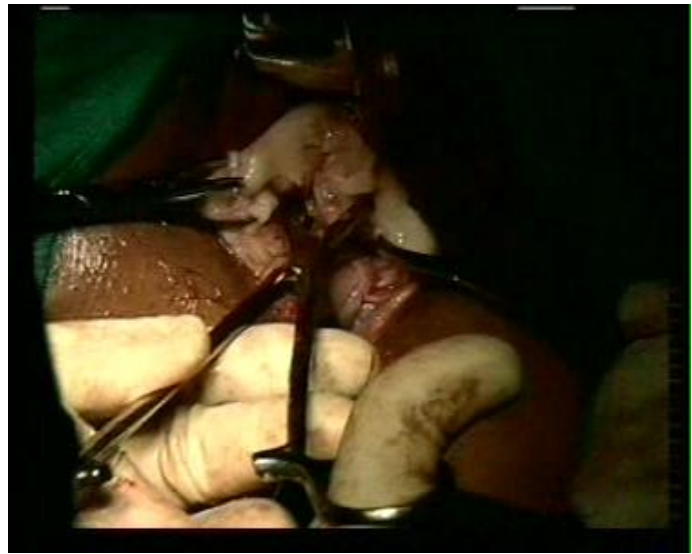

Figure 4: Debulking technique: morcellation.

\section{RESULTS}

The two groups were comparable in age and parity as shown in Table 1.

In both the groups Menorrhagia (96.67\% in NDVH, $76.6 \% \%$ in $\mathrm{TAH}$ ), was the main symptom followed by lump abdomen $(26.67 \%, 20 \%)$, and heaviness lower abdomen $(26.67 \% 26.6 \%)$ (Table-2).

There were more than one symptoms present in one patient. However, the main indication for surgery was fibroid uterus $(73.33 \%$ in $\mathrm{VH}, 76.67 \%$ in $\mathrm{TAH})$ followed by adenomyosis $(26.67 \%$ in $\mathrm{VH}, 20 \%$ in TAH) (Figure 5). The largest uterine weight in study group was $900 \mathrm{gm}$.

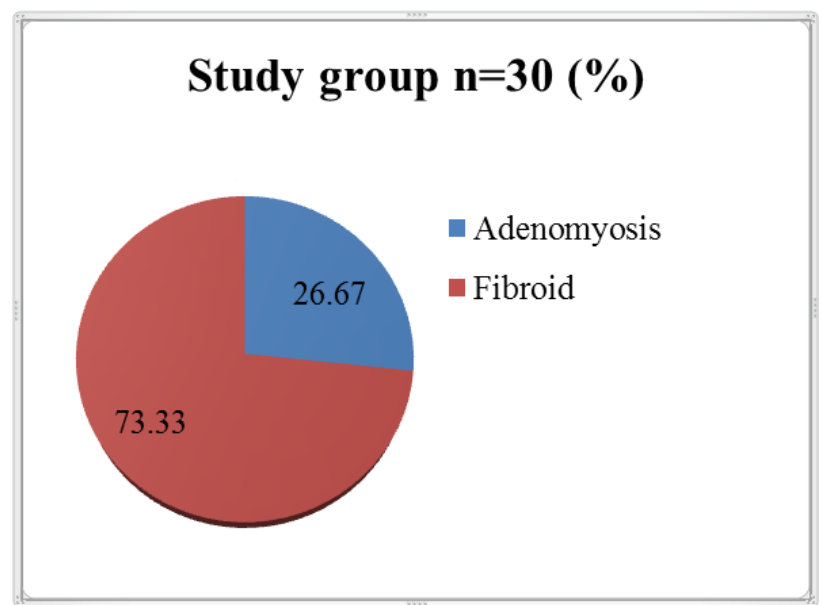

Figure 5: Indications of surgery.

Table 1: Age and parity.

\begin{tabular}{|c|c|c|c|c|c|}
\hline Age (years) & $\begin{array}{l}\text { Study group } \\
\mathbf{n}=\mathbf{3 0}(\%)\end{array}$ & $\begin{array}{c}\text { Control group } \\
n=\mathbf{3 0}(\%)\end{array}$ & Parity & $\begin{array}{l}\text { Study group } \\
\mathbf{n}=\mathbf{3 0}(\%)\end{array}$ & $\begin{array}{c}\text { Control group } \\
n=30(\%)\end{array}$ \\
\hline $35-40$ year & $11(36.67)$ & $4(13.33)$ & $1-3$ & 23 (76.67) & $24(80.00)$ \\
\hline 41-45year & 17 (56.67) & $24(80.00)$ & $4-6$ & $7(23.33)$ & $6(20.00)$ \\
\hline 46-50 year & $2(6.67)$ & $2(6.67)$ & & & \\
\hline
\end{tabular}


Table 2: Symptoms profile.

\begin{tabular}{|lll|}
\hline $\begin{array}{l}\text { Symptoms } \\
\text { Menorrhagia }\end{array}$ & $\begin{array}{l}\text { Study group } \\
n=30(\%)\end{array}$ & $\begin{array}{l}\text { Control group } \\
n=30(\%)\end{array}$ \\
\hline Pain abdomen & $29(96.67)$ & $23(76.67)$ \\
\hline Urinary complaints & $0(10.00)$ & $5(16.67)$ \\
\hline Bowel complaints & $0(0.00)$ & $0(0.00)$ \\
\hline lump abdomen & $8(26.67)$ & $0(0.00)$ \\
\hline Heaviness abdomen & $8(26.67)$ & $8(26.00)$ \\
\hline
\end{tabular}

There was no conversion to laparotomy in the NDVH group hence giving the success of $100 \%$. For debulking the uterus, bisection + myomectomy was used in maximum women $14(46.67 \%)$ followed by bisection in $7(23.33 \%)$, coring in $5(16.67 \%)$, myomectomy in 2 $(6.67 \%)$, and morcellation $2(6.67 \%)$. The mean uterine weight was $420.00 \mathrm{~g} \pm 117.24$ in the NDVH group and $454.33 \mathrm{~g} \pm 52.50$ in the TAH group (Figure 6).

The mean operative time was less for NDVH $(97 \pm 4.46$ minutes) as compared to TAH $(100 \pm 7.27)$, though it was not statistically significant $(\mathrm{P}=0.621)$. The mean blood loss which was calculated by both measurement and haemoglobin change showed significantly lesser in NDVH group as compare to TAH group $(327.33 \pm 58.54$ $\mathrm{ml}, 251.13 \pm 57.98 \mathrm{ml}, \mathrm{P}=0.000)$, The blood transfusions were also less in NDVH than TAH. Post-op pain measured by VAS scale and no. of diclofenac patches used was also significant less in NDVH group ( $\mathrm{P}$ $=0.001)$. We had no visceral injury in either group though postoperative fever and wound infection were more in the TAH group than NDVH group. Overall complications were less in NDVH than TAH $(6.66 \%$, $50 \%$ ) respectively (Table 3). Women in NDVH had lesser mean hospital stay (3.133 \pm 0.345 days, $4.67 \pm 1.09$ days, $\mathrm{P}=0.000$ ) when compared to TAH group.

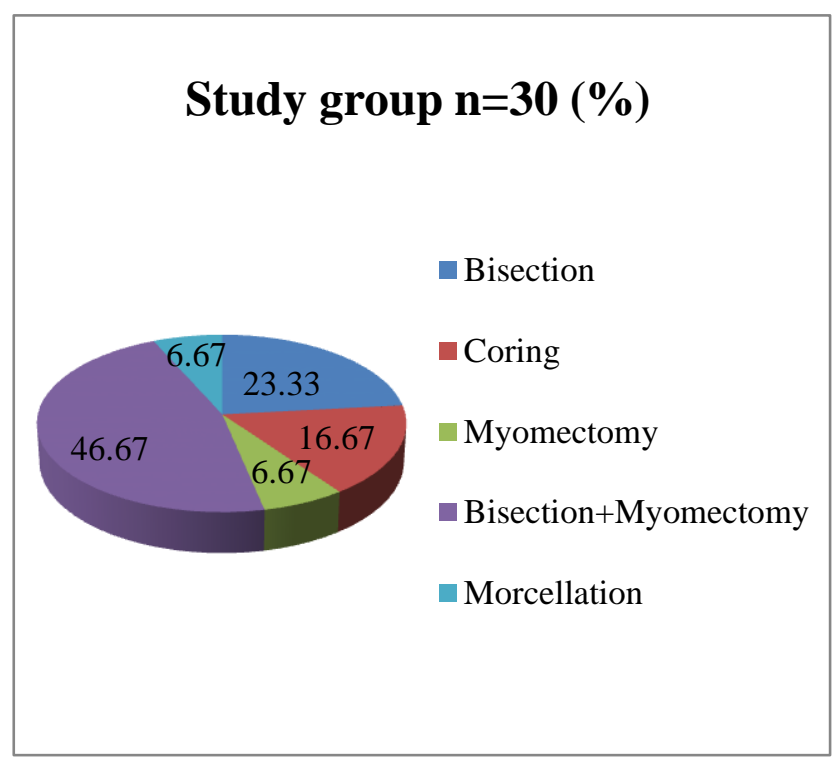

Figure 6: Debulking techniques.
Table 3: Surgical results.

\begin{tabular}{|llll|}
\hline Parameters & VH & TAH & $\begin{array}{l}\text { P } \\
\text { value }\end{array}$ \\
\hline $\begin{array}{l}\text { Average } \\
\text { operating time }\end{array}$ & $97 \pm 4.46 \mathrm{~min}$ & $100 \pm 7.27 \mathrm{~min}$ & 0.621 \\
\hline $\begin{array}{l}\text { Average blood } \\
\text { loss }\end{array}$ & $\begin{array}{l}251.13 \pm \\
57.98 \mathrm{ml}\end{array}$ & $\begin{array}{l}327.33 \pm 58.54 \\
\mathrm{ml}\end{array}$ & 0.000 \\
\hline $\begin{array}{l}\text { Average hospital } \\
\text { stay }\end{array}$ & $\begin{array}{l}3.133 \pm 0.345 \\
\text { days }\end{array}$ & $\begin{array}{l}4.67 \pm 1.09 \\
\text { days }\end{array}$ & 0.000 \\
\hline $\begin{array}{l}\text { Oral intake } \\
\text { hours }\end{array}$ & $\begin{array}{l}\text { hours } \\
\text { hours }\end{array}$ & 0.012 \\
\hline Postoperative complications & & \\
\hline $\begin{array}{l}\text { Fever } \\
\left.\text { (temp }>38^{\circ} \mathrm{C}\right)\end{array}$ & $2(6.67)$ & $10(33.33)$ & \\
\hline Wound sepsis & 0 & $5(16.67)$ & \\
\hline $\begin{array}{l}\text { Overall } \\
\text { complications }\end{array}$ & $2(6.66)$ & $15(50)$ & \\
\hline
\end{tabular}

Women in NDVH group returned to their normal house hold activities earlier than TAH group $(21.03 \pm 0.08$ days, $44.09 \pm 0.84$ days; $\mathrm{P}=0.003)$.

In the present study, Quality of Life (QoL) was assessed by SF36 questionnaire preoperatively and at 6 weeks and 3 months. At 6 weeks postoperatively, the mean physical component scoring and mental component scoring was significantly higher in the study group than control group. $(54.32 \pm 1.67,55.44 \pm 1.21 ; 52.28 \pm 1.40,53.64 \pm 1.51, \mathrm{P}$ $=0.00)$. This signifies that the patients who underwent vaginal hysterectomy had a better quality of life postsurgery.

\section{DISCUSSION}

Though our success rate was $100 \%$ but we faced challenges in three cases; once while opening pouch of Douglas due to adhesions and in another two difficulty in bisection and delivering the uterus due to large fundal fibroid and large posterior cervical fibroid. Success largely depends upon the selection criteria like mobility of the uterus, adnexal masses, pelvic adhesions, vaginal laxity etc., which we strictly followed leading to our $100 \%$ success. It is a well-known fact that $70 \%$ to $80 \%$ of hysterectomies are performed by abdominal route and vaginal approach is usually reserved for uterovaginal prolapse. The usual contraindications for vaginal hysterectomy are absence of significant uterovaginal prolapse, presence of uterine enlargement, adhesions and the need for oophorectomy. With adequate vaginal access and good uterine mobility, vaginal hysterectomy can be easily performed. The uterosacral and cardinal ligaments, situated in close proximity to the vaginal vault once clamped and cut produce first degree descent. Multiparity, lax tissues following multiple deliveries and decreased tissue tensile strength provide comfort to vaginal surgeon even in the presence of uterine enlargement. The other important reason for the lower proportion of hysterectomies performed vaginally is the 
presence of uterine enlargement with leiomyomas or adenomyosis. However, bulky uterus can be dealt with techniques like bisection, myomectomy or debulking. In our study we used debulking procedures in all 30 patients, bisection in $7(23.33 \%)$, coring in $5(16.67 \%)$, myomectomy in $2(6.67 \%)$, bisection + myomectomy in $14(46.67 \%)$, and morcellation 2 (6.67\%). Magos A et al. did bisection combined with myomectomy and morcellation in most cases and coring in two cases to obtain reduction in uterine size. ${ }^{6}$ Recently, Dewan $\mathrm{R}$ et al., Sahin et al., Ray et al. and Bhadra et al. also used one of the debulking techniques (Bisection, coring and myomectomy) in vaginal hysterectomy. ${ }^{7-10}$ Our study showed VH took less time as compared to TAH (97 \pm 4.46 minutes, $100 \pm 7.27 \mathrm{~min})$, though not statistically significant $(\mathrm{P}=0.621)$. Similar results were reported by Hwang et al. who reported $74 \pm 22 \mathrm{~min}$ for $\mathrm{VH}$ and $98 \pm$ 16 min for TAH with $\mathrm{P}<0.001 .^{11}$ Benassi et al. and Baratnur et al. also reported lesser time taken in $\mathrm{VH}$ as compared to TAH (86 min vs. $102 \mathrm{~min}, \mathrm{P}<0.001)$, $(65 \pm$ 26.5 min vs. $101 \pm 27.1 \mathrm{~min}, \mathrm{P}<0.001)$, respectively. ${ }^{12,13}$ The mean uterine weight in the above studies was less than 350 grams whereas uterine weight in our study was 420 grams in the NDVH group. Our study as well as studies by Benassi et al and Hwang et al., showed overall complication rate for vaginal hysterectomy lesser than abdominal hysterectomy. ${ }^{11,12}$ Post-operative hospital stay in our study was lesser in VH group as compare to TAH group (3.13 days, 4.67 days). Similar results were shown by Benassi et al, Bartanur et al and Hwang et al. ${ }^{11-13}$ Quality of life (QoL) was assessed by SF36 questionnaire at 6 weeks and 3 months. The mean physical component scoring and mental component scoring were significantly higher in the study group $(\mathrm{VH})$ than control group (TAH). $(54.32 \pm 1.67,55.44 \pm 1.21 ; 52.28 \pm 1.40,53.64$ $\pm 1.51, \mathrm{P}=0.00)$. This signifies that the patients who underwent vaginal hysterectomy had a better quality of life post-surgery. Only Silva-Filho et al. studied quality of life and showed lower postoperative quality-of-life scores in the TAH group when compared to the NDVH group in functional capacity $(\mathrm{P}=0.002)$, physical aspect $(\mathrm{P}=0.008)$ and pain $(\mathrm{P}=0.002) .{ }^{14}$ Our experience with $100 \%$ success rate and less complication rate in $\mathrm{VH}$ group confirms that very large uterine volume does not represent a real obstacle for a gynaecologic surgeon who has expertise in debulking techniques and vaginal operations. We therefore opine that NDVH should be practiced more by gynaecologist and should be included in training program for residents and postgraduates trainees.

\section{CONCLUSION}

NDVH is safe and should be offered as the first surgical choice in women with uterine enlargement due to benign reasons and non-prolapsed uterus and should be included in training program for residents and postgraduates trainees. It is definitely a surgical challenge worth the effort.
Funding: No funding sources

Conflict of interest: None declared

Ethical approval: The study was approved by the hospital ethics committee

\section{REFERENCES}

1. Garry R, Fountain J, Mason S, Hawc J, Napp V, Abbott J, et al. The evaluate study: two parallel randomized trials, one comparing laparoscopic with abdominal hysterectomy, the comparing laparoscopic with vaginal hysterectomy. Br Med J. 2004;328:12933.

2. Flory N, Bissonnette F, Binik YM. Psychosocial effects of hysterectomy: literature review. J Psychosom Res. 2005;59(3):117-29.

3. Nieboer TE, Johnson N, Lethaby A, Tavender E, Curr E, Garry R, et al. Surgical approach to hysterectomy for benign gynaecological disease. Cochrane Database Syst Rev. 2009 Jul;(3):CD003677.

4. American College of Obstetricians and Gynecologists. Choosing the route of hysterectomy for benign disease. ACOG Committee Opinion No. 444. Obstet Gynaecol. 2009;114:1156-8.

5. Nelson GH, Ashford C, Williamson R, Amburn SD. Method for calculating blood loss at vaginal delivery. South Med J. 1998;74:550-2.

6. Magos A, Bournas N, Sinha R, Richardson RE, O'Connor H. Vaginal hysterectomy for the large uterus. Br J Obstet Gynaecol. 1996 Mar;103(3):24651.

7. Dewan Rupali, Agarwal Shivani, Manisha. Nondescent vaginal hysterectomy: an experience. J Obstet Gynaecol India. 2004 Jul/Aug;54(4):376-8.

8. Yilmaz Sahin. Vaginal hysterectomy and oophorectomy in women with 12-20 weeks' size uterus. Acta Obstet Gynaecol Scand. 2007;86(11):1359-69.

9. Ray Alokananda, Pant Luna, Balsara Roshan, Chaudhury Rashmi. Non descent vaginal hysterectomy: a constant improving surgical art. J Obstet Gynaecol India. 2011 Apr;61(2):182-8.

10. Banasree Bhadra, Arun Paul Choudhury, Amit Tolasari, Nandi Nupur. Non descent vaginal hysterectomy (NDVH): personal experience in 158 cases. Al Ameen J Med Sci. 2011;4(1):23-7.

11. Hwang JL, Seow KM, Tsai YL, Huang LW, Hsieh BC, Lee C. Comparative study of vaginal, laparoscopically assisted vaginal and abdominal hysterectomies for uterine myoma larger then $6 \mathrm{~cm}$ in diameter or uterus weighting at least 450g: a prospective randomized study. Acta Obstet Gynaecol Scand. 2002;81:1132-8.

12. Benassi L, Rossi T, Kaihura CT, Ricci L, Bedocchi L, Galanti B, et al. Abdominal or hysterectomy for enlarged uterus: a randomized clinical trial. Am J Obstet Gynaecol. 2002;187:1561-5.

13. Sunanda Bhartanur. Comparative study of abdominal versus vaginal hysterectomy in non-descent cases. 
Intern J Gynaecol Obstet. 2011;15(2):DOI: 10.5580/293f.

14. Silva-Filho AL, Werneck RA, de Magalhães RS, Belo AV, Triginelli SA. Abdominal vs. vaginal hysterectomy: a comparative study of the postoperative quality of life and satisfaction. Arch Gynaecol Obstet. 2006 Apr;274(1):21-4.

DOI: $10.5455 / 2320-1770 . i j r \operatorname{cog} 20141239$

Cite this article as: Mittal P, Andiliya A, Bansiwal R, Suri J, Singal S. Enlarged uterus through a natural orifice: worth an effort? A randomized controlled trial. Int J Reprod Contracept Obstet Gynecol 2014;3:1076-81. 